\title{
Indomethacin responsive hypercalcaemia associated with a renal sarcoma
}

\author{
J Gibbs, M J Dillon, S Lang, S Meghii, J Pritchard
}

\begin{abstract}
An infant presented with a non-metastatic renal spindle cell sarcoma and hypercalcaemia, which resolved after treatment with indomethacin. There was in vivo and in vitro evidence that hypercalcaemia was mediated by circulatory prostaglandins.
\end{abstract}

In adults, tumour derived polypeptides such as tumour necrosis factor, interleukin-1, transforming growth factor alpha (TGF- $\alpha$ ) and parathormone related peptide (PTHrP) have been shown to act as tumour derived humoral mediators of hypercalcaemia. ${ }^{1}$ A similar role has also been proposed for prostaglandins but overall results of treatment with prostaglandin inhibitors have been disappointing. ${ }^{2}$

'Humoral' hypercalcaemia only rarely accompanies malignancy in childhood, and tends to occur with unusual tumours. ${ }^{3}$ We report the case of an infant with a prostaglandin producing renal sarcoma and hypercalcaemia responsive to indomethacin.

\section{Case report}

A 6 month boy presented with irritability and poor appetite for one month. His mother had noticed an abdominal swelling a week previously. On examination he was pale and had moderate abdominal distension due to a large, right sided abdominal mass. Haemoglobin concentration was $91 \mathrm{~g} / \mathrm{l}$, white cell count $19.4 \times 10^{9} / 1$ with a normal differential and platelets $580 \times 10^{9} / 1$. Plasma urea concentration was $7.9 \mathrm{mmol} / \mathrm{l}$ and creatinine $63 \mu \mathrm{mol} / \mathrm{l}$. The plasma calcium concentration was raised at 3.91 $\mathrm{mmol} / \mathrm{l}$, with normal concentrations for plasma albumin $(37 \mathrm{~g} / \mathrm{l})$ and phosphate $(1.40 \mathrm{mmol} / \mathrm{l})$ and alkaline phosphatase activity (268 U/l). Serum total parathyroid hormone was $180 \mathrm{ng} / 1$ (normal range for age 120-380 ng/l), and 25hydroxyvitamin D $52.9 \mathrm{nmol} / 1$ (normal range for age 7.5-75.0 $\mathrm{nmol} / \mathrm{l}$ ). Chest radiography showed a raised right hemidiaphragm with some associated basal collapse, but no lung metastases. Renal ultrasound demonstrated a large, partly cystic right renal mass. Computed tomography showed that the mass crossed the midline in front of the aorta and extended down into the pelvis. Skeletal survey was normal.

Intravenous hydration was commenced, then frusemide added. After four days the hypercalcaemia persisted (fig 1) so indomethacin was administered ( $2 \mathrm{mg} / \mathrm{kg} /$ day in four divided doses). Over the next three days the plasma calcium fell to within the normal range, before

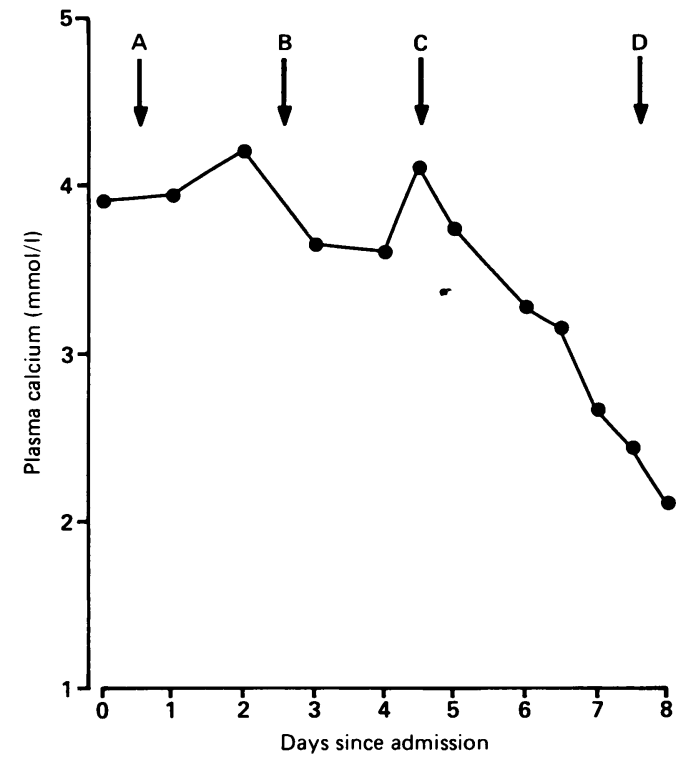

Figure 1 Serial plasma calcium measurements: (A) intravenous hydration started, (B) frusemide started, (C) indomethacin started, and (D) nephrectomy. After nephrectomy serum calcium remained normal.

surgery (fig 1). At operation, only a small amount of normal renal tissue lay stretched over the upper pole of the tumour. Right nephrectomy was performed, the excised specimen weighing $1035 \mathrm{~g}$. Histological examination showed a malignant tumour composed of undifferentiated spindle shaped cells with a high mitotic count, interspersed with loose myxoid mesenchymal areas. Extensive foci of necrosis were present and tumour eroded the surrounding pseudocapsule in several areas. Immunohistochemical studies showed positive vimentin staining in the tumour cells only and electron microscopic appearances were non-specific. No histological or ultrastructural evidence of malignant rhabdoid tumour was present. The tumour was therefore classified as an 'undifferentiated sarcoma'.

After nephrectomy, a nine month course of combination chemotherapy (pulses of vincristine, actinomycin D, and cyclophosphamide alternating with etoposide, vincristine, and doxorubicin) was given. One year after completion of treatment the child remains well, normocalcaemic, and free from tumour recurrence.

\section{Methods}

Fragments of tumour $\left(1 \mathrm{~mm}^{2}\right)$ were incubated for three days in $25 \mathrm{~cm}^{2}$ flasks (Sterilin) each with $5 \mathrm{ml}$ of Eagle's modified essential medium (Gibco). Medium was then removed and half 


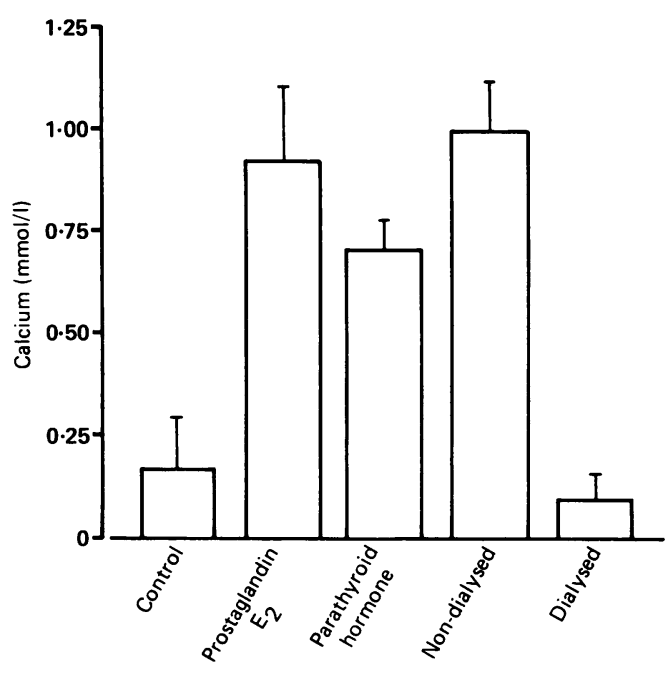

Figure 2 Effect of non-dialysed and dialysed tumour explant supernatants (1:10 dilution) on bone resorption in vitro. Positive controls were prostaglandin $E_{2}\left(10^{-6} M\right)$ and parathyroid hormone $\left(10^{-8} M\right)$. The difference between results with dialysed and non-dialysed samples is significant $(p=<0.05 ;$ Student's $t$ test $)$.

was dialysed using benzolyated dialysis tubing (cut off point 2000 molecular weight; Sigma). In vitro bone resorption was assayed by colorimetric measurement of calcium release from five day old mouse calvaria, incubated for $\mathbf{4 8}$ hours with control media and with tumour media (both dialysed and non-dialysed.) ${ }^{4}$ Prostaglandin $\mathrm{E}_{2}$ was measured by radioimmunoassay: tritiated prostaglandin $E_{2}$ was obtained from Amersham International UK, antiserum from Steranti, and standards from Sigma.

\section{Results}

Before indomethacin treatment the concentration of urinary prostaglandin $\mathrm{E}_{2}$ was $1034 \mathrm{pg} /$ mmol creatinine. During indomethacin treatment it fell to $609 \mathrm{pg} / \mathrm{mmol}$ creatinine, coincident with a reduction in plasma calcium (fig 1). At nephrectomy, before ligation of the vessels, the renal arterial:venous prostaglandin $\mathbf{E}_{2}$ concentrations were $500: 2000 \mathrm{pg} / \mathrm{ml}$. The renal tumour contained $56 \mathrm{ng}$ prostaglandin $\mathrm{E}_{2} / \mathrm{mg}$ wet weight compared with $1.0 \mathrm{ng}$ prostaglandin $E_{2} / m g$ wet weight of normal renal tissue. ${ }^{4}$

The undialysed tumour explant medium caused significant in vitro bone resorption (fig 2), comparable with the media containing either prostaglandin $E_{2}$ or parathyroid hormone. In contrast, the dialysed sample of the same medium caused no bone resorption indicating that the active molecule was $<2000$ molecular weight (the molecular weight of prostaglandin is 300-500).

\section{Discussion}

Hypercalcaemia in malignancy may result from either the release of calcium from sites of widespread bone metastasis or from the release of tumour derived humoral factors that cause panskeletal bone resorption. In the absence of evident bone metastases, a humoral cause for our patient's hypercalcaemia seemed likely. Humoral hypercalcaemia has been reported in association with two rare types of childhood renal tumours: mesoblastic nephroma and malignant rhabdoid tumour. Some tumours have been shown to produce either prostaglan$\operatorname{din} \mathrm{E}_{2}{ }^{45}$ or parathyroid hormone. ${ }^{6}$ However, there are no previous reports of the use of prostaglandin inhibitors in management.

The role of circulating prostaglandin in the production of malignancy associated humoral hypercalcaemia is still controversial. ${ }^{1}$ Prostaglandins and their metabolites have short plasma half lives and may act indirectly by stimulating other cells to release bone resorbing factors. In our patient there was strong evidence that prostaglandin $E_{2}$ was involved in the pathogenesis of the hypercalcaemia. Firstly, the tumour contained significant amounts of prostaglandin $E_{2}$ and caused bone resorption in vitro. Secondly, there was a substantial arteriovenous gradient across the tumour. Thirdly, the patient's serum calcium concentration fell to normal after the administration of indomethacin, with the tumour still in situ, coincident with a reduction in urinary prostaglandin $\mathrm{E}_{2}$ excretion.

To our knowledge, this is the first report of hypercalcaemia associated with a non-metastatic sarcoma in childhood, and is in line with previous observations that this is a complication of unusual childhood tumours. The evidence that prostaglandin $\mathrm{E}_{2}$ was implicated in its pathogenesis, and the clinical response to indomethacin, provide a treatment alternative for future similar cases of tumour associated humoral hypercalcaemia.

We thank Vanita Shah for technical help, Dr Wil Harvey for providing advice and Dr Howard Fleet for referring the patient. We also acknowledge financial support from the Gillian Fabb Memorial Fund and from the Imperial Cancer Research Fund. Sheila Giles kindly typed the manuscipt.

1 Ralston S. Pathogenesis of humoral hypercalcaemia of malignancy. Lancet 1987; ii: 1443-5.

2 Brenner DE, Harvey HA, Lipton A, Demers L. A study of PGE2, parathormone and response to indomethacin in patients with hypercalcemia of malignancy. Cancer 1982; patients with

3 Leblanc A, Callaud JM, Hartmann O, et al. Hypercalcaemia preferentially occurs in unusual forms of childhood nonHogdkins lymphoma, rhabdomyosarcoma and Wilms tumour. Cancer 1984;54:2132-6.

4 Mitchell CD, Harvey W, Gordon D, Womer RB, Dillon MJ, Pritchard J. Rhabdoid Wilms' tumour and prostaglandinmediated hypercalcaemia. European Paediatric Haematology and Oncology 1985;2:153-7.

5 Vido L, Carli M, Rizzoni G, et al. Congenital mesoblastic nephroma with hypercalcaemia. Am $\mathcal{F}$ Pediatr Hematol Oncol 1986;8:149-52.

6 Mayes LC, Kasselberg A, Roloff JS, Lukens JN. Hypercalcemia associated with immunoreactive parathyroid hormone in a malignant rhabdoid tumour of the kidney. Cancer 1984;54:882-4. 